\title{
Curcumin inhibits cellular condensation and alters microfilament organization during chondrogenic differentiation of limb bud mesenchymal cells
}

\author{
Dongkyun Kim ${ }^{1}$, Song-Ja Kim, \\ Shin-Sung Kang ${ }^{3}$ and Eun-Jung Jin ${ }^{1,2,5}$ \\ ${ }^{1}$ Department of Biological Sciences \\ College of Natural Sciences \\ ${ }^{2}$ Institute of Biotechnology \\ Wonkwang University \\ Iksan 570-749, Korea \\ ${ }^{3}$ Department of Biological Sciences \\ College of Natural Sciences \\ Kyungpook National University \\ Daegu 702-701, Korea \\ ${ }^{4}$ Department of Life Sciences \\ College of Natural Sciences \\ Kongju National University \\ Chungnam 314-701, Korea \\ ${ }^{5}$ Corresponding author: Tel, 82-63-850-6197; \\ Fax, 82-63-857-8837; E-mail, jineunjung @ wku.ac.kr \\ DOI 10.3858/emm.2009.41.9.072
}

Accepted 11 May 2009

Abbreviations: ECM, extracellular matrix; FAK, focal adhesion kinase; MMP, matrix metalloprotease; PNA, peanut agglutinin

\begin{abstract}
Curcumin is a well known natural polyphenol product isolated from the rhizome of the plant Curcuma longa, anti-inflammatory agent for arthritis by inhibiting synthesis of inflammatory prostaglandins. However, the mechanisms by which curcumin regulates the functions of chondroprogenitor, such as proliferation, precartilage condensation, cytoskeletal organization or overall chondrogenic behavior, are largely unknown. In the present report, we investigated the effects and signaling mechanism of curcumin on the regulation of chondrogenesis. Treating chick limb bud mesenchymal cells with curcumin suppressed chondrogenesis by stimulating apoptotic cell death. It also inhibited reorganization of the actin cytoskeleton into a cortical pattern concomitant with rounding of chondrogenic competent cells and down-regulation of integrin $\beta 1$ and focal adhesion kinase (FAK) phosphorylation. Curcumin suppressed the phosphorylation of Akt leading to Akt inactivation. Activation of
\end{abstract}

Akt by introducing a myristoylated, constitutively active form of Akt reversed the inhibitory actions of curcumin during chondrogenesis. In summary, for the first time, we describe biological properties of curcumin during chondrogenic differentiation of chick limb bud mesenchymal cells. Curcumin suppressed chondrogenesis by stimulating apoptotic cell death and down-regulating integrin-mediated reorganization of actin cytoskeleton via modulation of Akt signaling.

Keywords: apoptosis; cell differentiation; chondrocytes; curcumin; cytoskeleton; microfilament; protooncogene proteins c-akt

\section{Introduction}

The progressive degeneration of articular cartilage, indicating a disruption of the balance between anabolic and catabolic activities of the chondrocytes, results in osteoarthritis, a painful, debilitating disease of the synovial joints. Several events are known to play significant roles for the initiation and progression of joint diseases, including dysregulation of pro-inflammatory cytokines, pro-inflammatory enzymes that mediate the production of prostaglandins and leukotrienes (e.g. lipo-oxygenase), together with the expressions of adhesion molecules and matrix metalloproteinases. Curcumin is the major pigment derived from the rhizome of turmeric Curcuma longa Linn and has been found to exert various biological effects, such as anti-inflammatory, anti-oxidant and anti-tumorigenic effects, in addition to tissue repair and wound healing (Khanna, 1999). Even though the exact mechanisms involved in anti-inflammatory action in the degeneration of articular cartilage to relieves the aches and pains associated with arthritis are not fully understood, may recent studies provide a better understanding of theses mechanism and new insight into the field of arthritis. However, the role of curcumin in the differentiation of chondrogenic progenitor cells has not been studied even though their characteristics much differ from articular chodrocytes.

During embryonic development, most bones form by endochondral ossification, in which bones are first laid down as cartilage precursors (Karsenty 
and Wagner, 2002). This is a precise series of events that includes aggregation and differentiation of mesenchymal cells, proliferation, hypertrophy and death of chondrocytes (DeLise et al., 2000). In particular, chondrogenesis is characterized by 2 dramatic changes in cellular condensation that are mediated by cell-cell and cell-matrix adhesion molecules (Sandell and Adler, 1999; DeLise et al., 2000; Knudson and Knudson, 2001) and cell shape changes from fibroblastoid to round or polygonal morphologies (von der Mark and von der Mark, 1977).

Several studies have shown that curcumin modulates the activities of numerous targets, including growth factors, growth factor receptors, transcription factors, cytokines, enzymes and genes regulating apoptosis (Gertsch et al., 2003; Balasubramanian and Eckert, 2006; Zheng and Chen, 2006). It also suppresses the proliferation of a number of transformed cell types in vitro, including breast (Simon et al., 1998; Ramachandran and You, 1999), colon (Chen et al., 1999) and oral epithelial cells
(Khafif et al., 1998). The anti-proliferative effects of curcumin include blocks at specific cell cycle stages, particularly a G2/M block (Hanif et al., 1997; Mehta et al., 1997; Ramachandran and You, 1999; Holy, 2002). Curcumin has also been reported to inhibit apoptosis in several cell types (Yamamoto, 1995; Sikora et al., 1997) suggesting cell type-specific effects of curcumin during cell death triggering.

The signaling mechanisms of curcumin action are beginning to be elucidated. Curcumin is known to inhibit a number of kinase and enzyme activities, including PKC (Liu et al., 1993), phosphorylase kinase (Reddy and Aggarwal, 1994), EGF receptor and erbB2, (Korutla and Kumar, 1994; Korutla et al., 1995; Hong et al., 1999). In spite of recent studies, large gaps exist in our knowledge of how curcumin functions during chondrogenesis. In particular, little information is available regarding the effects of curcumin on cytoskeletal organization or overall cell behavior.

In this study, we applied a high density (micro-

A
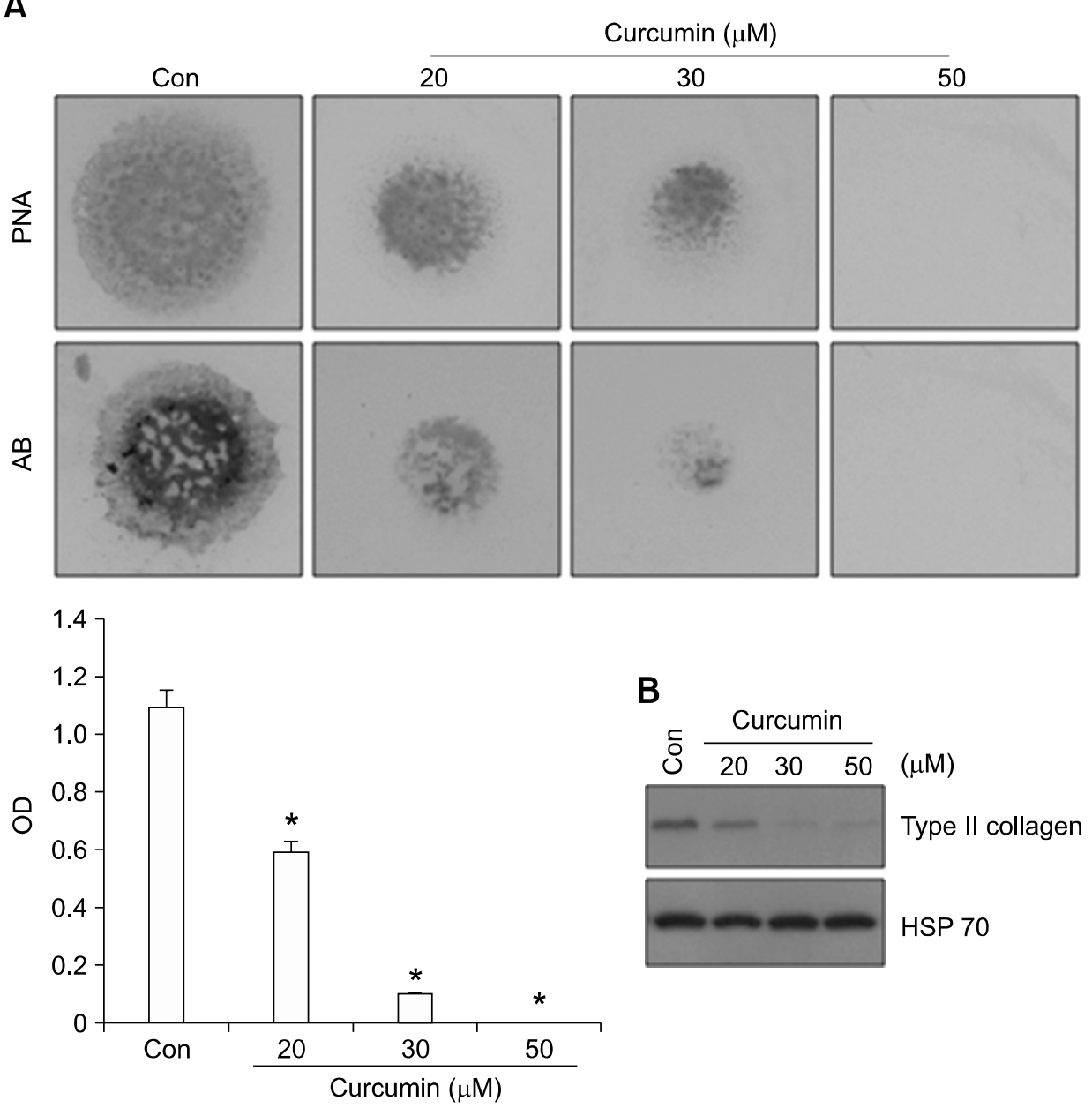

Figure 1. Curcumin suppresses chondrogenesis. (A) PNA and Alcian blue staining of chick limb bud mesenchymal cells grown in micromass cultures in the presence of varying concentrations of curcumin (upper panel) on day 3 and day 5 of cultures respectively. Quantification of chondrogenesis was determined by measuring the absorbance of bound Alcian blue at $600 \mathrm{~nm}$ (lower panel). (B) Changes in the levels of type II collagen in control and curcumin-treated cultures were determined by Western blotting on day 5 of culture. Results shown are representative of at least 4 independent experiments. HSP 70 was used as a loading control. *, statistically significant differences compared with control cells $(P<0.01)$. 
mass) culture model system that allowed differentiation of chondrogenic progenitors into chondrocytes to clarify a mechanistic role for curcumin during chondrogenesis. For the first time, we found that curcumin suppressed chondrogenesis by stimulating apoptotic cell death, down-regulating integrin $\beta 1$ and lowering the phosphorylation level of FAK. This, in turn, lead to reorganization of the actin cytoskeleton via modulation of Akt signaling.

\section{Results}

\section{Curcumin inhibits chondrogenesis by stimulating apoptotic death of chondrogenic competent cells}

To determine any effects of curcumin on chondrogenesis, chondroblasts isolated from wing buds were cultured at a density of $2 \times 10^{7}$ cells $/ \mathrm{ml}$ and stimulated with varying concentrations of curcumin. Precartilage condensation and chondrogenesis were assessed by peanut agglutinin (PNA) binding on day 3 and by Alcian blue staining for sulfated proteoglycans on day 5, respectively. At curcumin concentrations $>20 \mu \mathrm{M}$, PNA staining and Alcian blue uptake (Figure 1A) were significantly decreased. We therefore used $20 \mu \mathrm{M}$ curcumin for all subsequent experiments. A significant decrease in type II collagen expression in curcumin-treated cultures, as compared with control cultures (Figure $1 \mathrm{~B})$, was consistent with this observation. These results demonstrate that curcumin inhibits sulfated proteoglycan accumulation and cartilage nodule formation during chondrogenesis.

Chondrogenic differentiation is known to be re-

$\mathbf{A}$

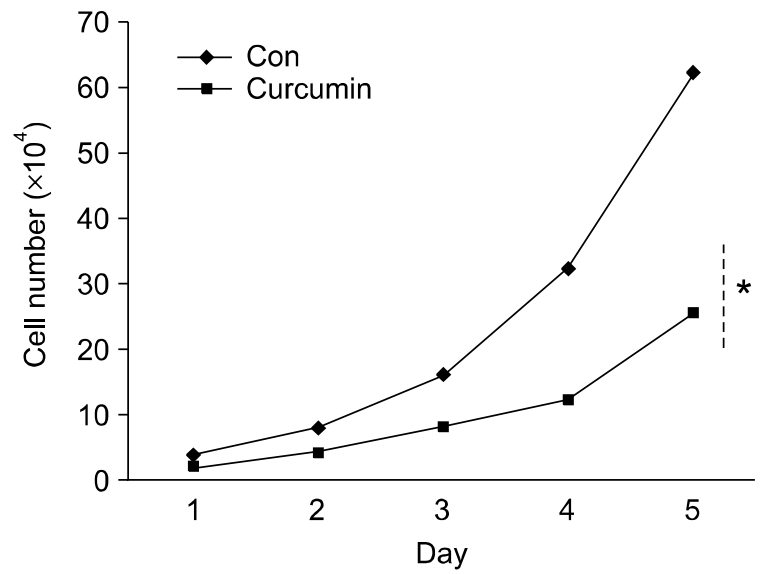

gulated at 3 stages: cell proliferation, precartilage condensation and cartilage nodule formation (Solursh, 1989; Maini and Solursh, 1991). We first examined if curcumin-inhibited chondrogenesis was due to regulation of cell proliferation. During chondrogenic differentiation, the cell numbers increased in control cultures. Exposure of cells to curcumin suppressed the proliferation of chondrogenic competent cells as determined by direct cell counting (Figure 2A) and FACS analysis (Figure 2B). These results indicate that the negative regulatory action by curcumin results by modulating the proliferation and survival of chondrogenic competent cells.

\section{Curcumin alters cytoskeletal reorganization in chick limb bud mesenchymal cells during chondrogenesis}

Our laboratory previously showed that reorganization of the actin cytoskeleton to a cortical pattern concomitant with rounding of cells and reduced numbers of stress fibers occurs with time in culture (Jin et al., 2007). We also demonstrated that microtubule polymerization is absolutely required for later stages of chondrogenic differentiation. Therefore, we investigated if suppressed chondrogenic differentiation by curcumin was also associated with the reorganization of the actin cytoskeleton. Actin stress fibers were markedly intensified by treatment with curcumin compared to the control (Figure 3A). This pointed to the actin cytoskeletal reorganization for curcumin-suppressed chondrogenesis.

Three structural elements are required for cell morphological changes, including an extracellular matrix (ECM) ligand, its cell surface receptor and
B

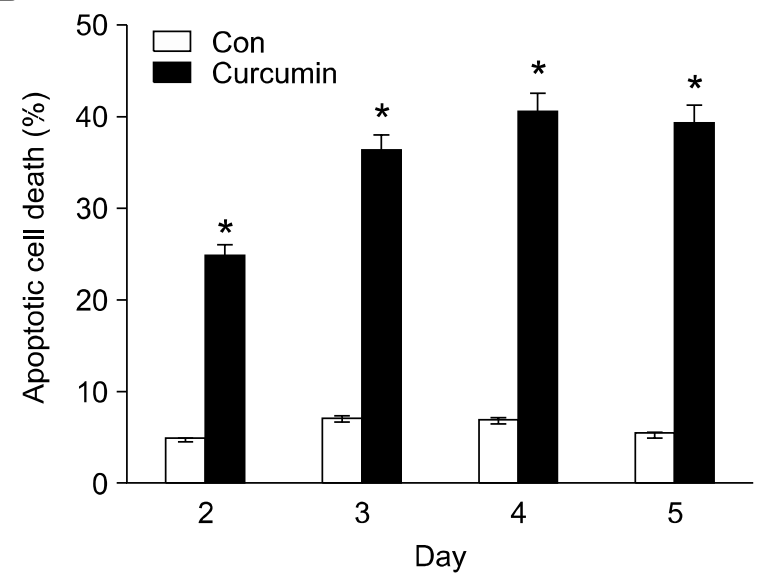

Figure 2. Curcumin induces apoptotic death of chondrogenic competent cells. Chick limb bud mesenchymal cells were cultured with or without $20 \mu \mathrm{M}$ curcumin. (A) The number of viable cells was counted on the indicated days. (B) Percentages of apoptotic cells were quantified by flow cytometric analysis on days 2 and 3 of culture. Results are averages with standard deviations of 5 independent experiments. *, statistically significant differences compared with control cells $(P<0.01)$. 
the cell cytoskeleton. Recent studies have shown that members of the integrin family, including the $\alpha 5 \beta 1$ fibronectin receptor, $\alpha 2 \beta 1$ and $\alpha 3 \beta 1$, and the vitronectin receptor $\alpha \mathrm{v} \beta 3$ interact reversibly with both ECM proteins and cytoskeletal structures ( $\mathrm{Li}$ et al., 2004). Therefore, actin cytoskeleton reorganization could be regulated by the type of receptor-ligand interactions. First, possible curcumin-induced alterations of fibronectin and integrin $\beta 1$ expressions in chick wing bud mesenchymal cells were examined by immunoblotting (Figure 3B). The level of fibronectin remained unchanged after curcumin treatment. However, integrin $\beta 1$ expression in chick wing bud mesenchymal cells was completely abolished. Furthermore, the engagement of integrins to the ECM triggers the activation of protein tyrosine kinases (Felsenfeld et al., 1999; Parsons et al., 2002). The phosphorylation levels of focal adhesion kinase (FAK) were also decreased by curcumin (Figure 3B).

\section{Involvement of Akt signaling in curcumin-suppressed chondrogenic differentiation of chick limb bud mesenchymal cells}

Activation of Akt has been shown to block the actions of several pro-apoptotic proteins, such as Bad (Hayakawa et al., 2000), and block cytochrome $C$ release from the mitochondria through the regulation of $\mathrm{Bcl}-2$ (Davies et al., 1999). Previously, we demonstrated that Akt signaling positively regulates chondrogenic differentiation of chick limb bud mesenchymal cells via reorganization of the actin cytoskeleton to a cortical pattern with concomitant rounding of chondrogenic competent cells (Jin et al., 2007). Therefore, we investigated if Akt signaling was associated with curcumin-suppressed chondrogenic differentiation. No obvious changes in Akt protein levels were observed. However, the phosphorylation level of Akt was decreased when cells were exposed to curcumin (Figure 4A).

To further verify Akt involvement in curcuminsuppressed chondrogenic differentiation, chondrogenic progenitors were transfected with vectors expressing either a myristoylated constitutively active form of Akt (myr-Akt), a dominant inhibitory mutant Akt (mutant-Akt) or an empty vector (mock). Compared to cultures treated with curcumin alone, activation of Akt after introducing myr-Akt showed recoveries of precartilage condensation (Figure 4B upper panel), chondrogenic differentiation (Figure 4B lower panel), apoptotic cell death (Figure 4C), expression levels of pFAK and integrin $\beta 1$ (Figure 4D), and rounding of cells (surrounded by dotted circle in Figure 4E). In contrast, inhibition of Akt by introducing mutant-Akt was associated with even
A

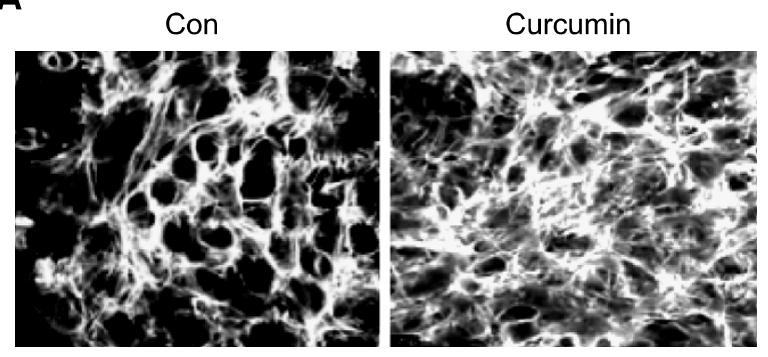

B

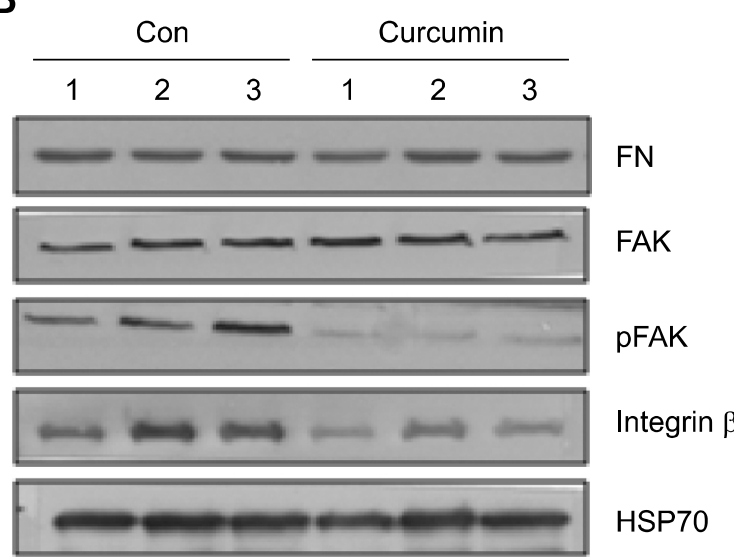

Figure 3. Curcumin suppresses reorganization of the actin cytoskeleton during chondrogenesis of chick limb bud mesenchymal cells. Chick limb bud mesenchymal cells were cultured with or without $20 \mu \mathrm{M}$ curcumin. (A) Cells were immunostained for F-actin using Alexa488-phalloidin on 4 days of culture. (B) Changes in the levels of pFAK ${ }^{397} F A K$, paxillin and integrin $\beta 1$ in control and curcumin-treated cultures were determined by Western blotting on the indicated days. Results shown are representative of at least 4 independent experiments.

greater decreases of precartilage condensation, chondrogenic differentiation, apoptotic cell death, and expression levels of pFAK and integrin $\beta 1$ compared to cultures treated with curcumin alone. The formation of stress fiber was also intensively increased by inhibition of Akt compared to cultures treated with curcumin alone.

\section{Discussion}

Curcumin has been shown to inhibit cell growth and to have a number of biological effects, such as anti-metastatic, anti-inflammatory and anti-infectious (Kuo et al., 1996; Jaruga et al., 1998; Kawamori et al., 1999). However, the essential cellular and molecular targets and a signaling mechanism for curcumin have not been completely defined. Here, we demonstrate several biological properties of curcumin by showing that curcumin suppressed chondrogenic differentiation of chick limb mesenchymal cells by stimulating apoptotic cell death and 
A

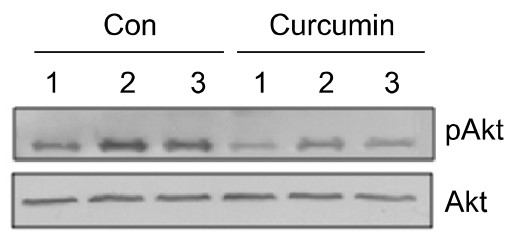

B
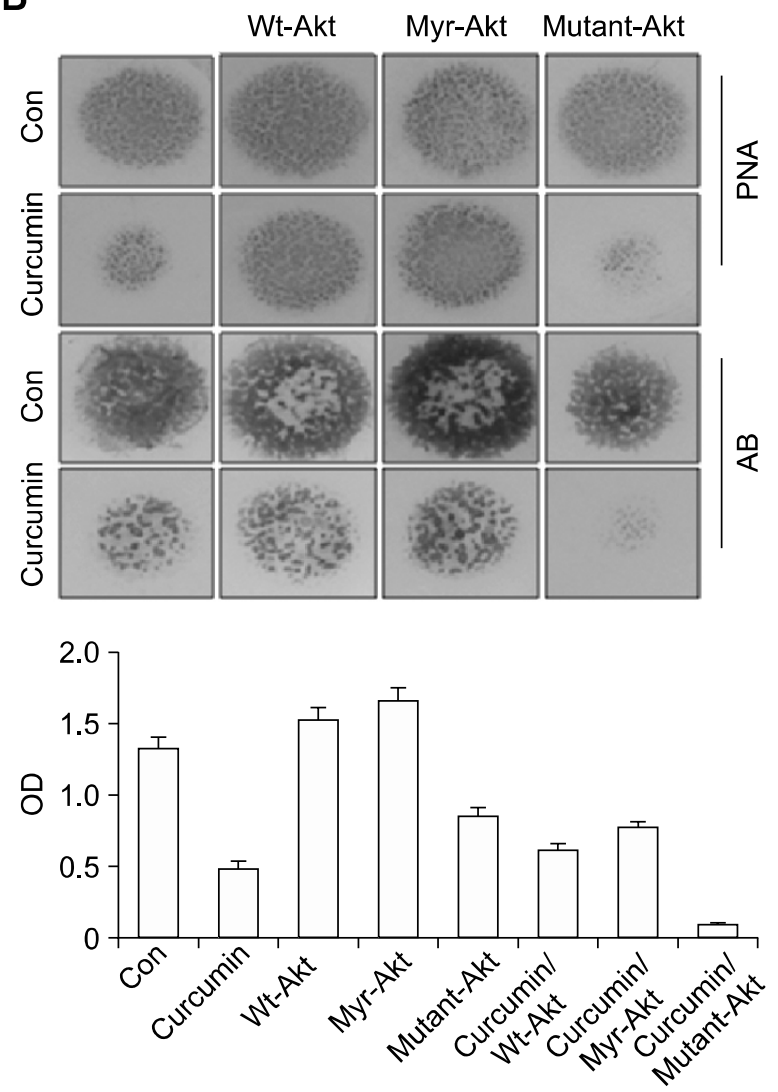

C

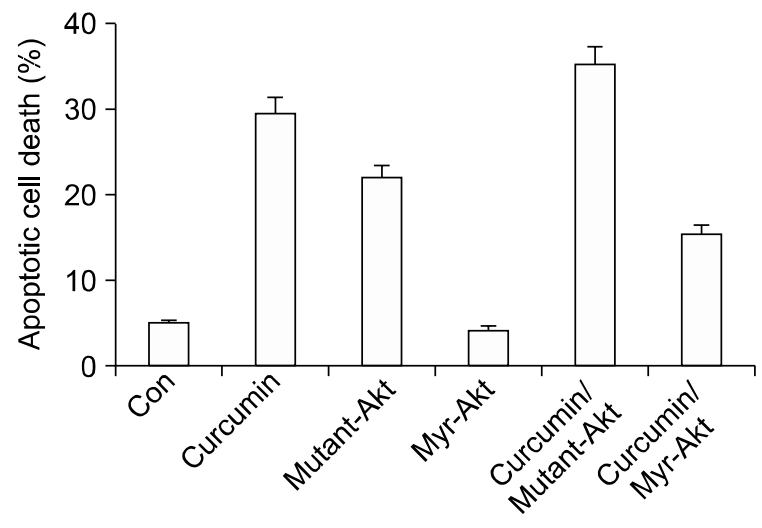

D

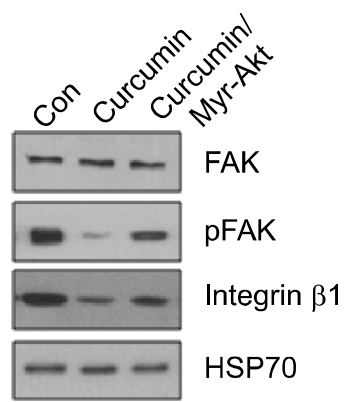

E

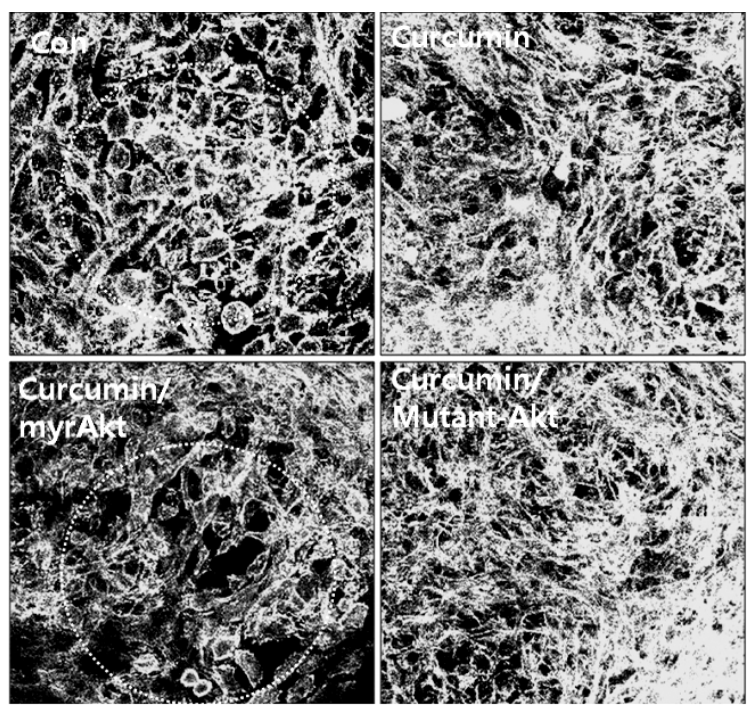

Figure 4. Akt signaling mediates inhibitory actions of curcumin during chondrogenesis. Chick limb bud mesenchymal cells were cultured with or without $20 \mu \mathrm{M}$ curcumin. (A) Changes in the levels of Akt or pAKt in control and curcumin-treated cultures were determined by Western blotting on the indicated days. (B-E) Chondrogenic progenitors were electroporated with vectors expressing either a myristoylated constitutively active form of Akt (myr-Akt), a dominant inhibitory mutant Akt (mutant-Akt) or an empty vector (mock) using a square wave generator (BTX-830; Gentronics, San Diego, CA) with 20 msec, 200 square pulses. (B) Cells were stained with PNA or Alcian blue on day 3 or 5 of culture, respectively. (C) Percentages of apoptotic cells were quantified by flow cytometric analysis on day 3 of culture. (D) Changes in the levels of pFAK ${ }^{397}$ FAK, and integrin $\beta 1$ were determined by Western blotting. (E) Cells were immunostained for F-actin using Alexa488-phalloidin on 4 days of culture. Notice many rounding cells inside dotted circle in control- or curcumin/myr-Akt-treated culture. 
altering actin cytoskeleton reorganization, possibly by down-regulating Akt signaling.

Curcumin induces apoptosis in a variety of cells, including prostate cancer cells (Dorai et al., 2004, Guo et al., 2006). Curcumin is known to induce the up-regulation of pro-apoptotic proteins of the $\mathrm{Bcl}-2$ family and the down-regulation of anti-apoptotic proteins Bcl-2 and Bcl-xL in cancer cells, including U937 cells (Bae et al., 2003), human renal Caki cells (Woo et al., 2003) and DU145 cells (Mukhopadhyay et al., 2001). Consistent with these observations, we also found that curcumin induced apoptosis of chondrogenic progenitors in chick limb buds.

Actin filaments are integral components of the plasma membrane-associated cytoskeleton and are thought to play important roles in the determination of cell polarity, shape and membrane mechanical properties (Swailes et al., 2004; Wawro et al., 2007). Chondrogenesis is characterized by dramatic changes in cell shape from fibroblastoid to round or polygonal morphologies (von der Mark and von der Mark, 1977). Undifferentiated chondrogenic progenitor cells are characterized by pronounced fibrillar actin fibers, whereas chondrocytes display a primarily cortical organization of their actin filaments (Idowu et al., 2000; Langelier et al., 2000). Previously, we demonstrated that actin cytoskeleton reorganization is essential for chondrogenic differentiation of chick limb bud mesenchymal cells (Jin et al., 2007). Here, we demonstrate an additional biological property of curcumin, showing that actin stress fibers were markedly intensified by curcumin treatment, which points to a negative regulatory role for curcumin in the reorganization of the actin cytoskeleton.

Although the precise mode of curcumin action is not yet elucidated, a few signaling pathways and molecular targets have been suggested, and the results often appear to be cell-type specific and dose-dependent (Bernt et al., 2006; Lev-Ari et al., 2006). Previously, our laboratory showed that chondrogenic differentiation of chick limb bud mesenchymal cells is regulated by complex protein kinase signaling cascades involving PKC, MAPKs and Akt (Choi et al., 1995; Chang et al., 1998; Oh et al., 1999; Yoon et al., 2000). Curcumin has been shown to inhibit tyrosine kinase activity in AU565 tumor cells (Narasimhan and Ammanamanchi, 2008). Pre-treatment of MCF-7 cells with curcumin resulted in an inhibition of TNF- $\alpha$-induced JNK activation (Chen and Tan, 1998). In this study, treatment of chondrogenic progenitors with curcumin inhibited Akt phosphorylation, indicating that the Akt pathway contributed to curcumin-modulated chondrogenic differentiation of chick limb bud mesenchymal cells.

The phosphorylation of Akt is routinely used as an indicator of Akt activation. Suppression of Akt activation promoted apoptotic cell death. It also hindered integrin-mediated signal transduction by the down-regulation of integrin $\beta 1$ and lowering the phosphorylation level of FAK, which in turn lead to reorganization of the actin cytoskeleton. However, exactly how curcumin exerts its inhibitory activity on chondrogenesis is still little understood.

It has been reported that a mixture of curcuminoids inhibited the expression of gelatinase $B$ (matrix metalloprotease-9, MMP-9) in endothelial cells (Mohan et al., 2000). MMP-9 can be regulated via AP-1, PI3K/PKB and GSK-3 $\beta$ (Troussard et al., 2000; Kim et al., 2001). The first report that curcumin has potential against arthritis was in 1980 (Deodhar et al.,1980). Neutral matrix MMPs responsible for degradation of cartilage in arthritis were inhibited by curcumin (Onodera et al., 2000). Previously, we also demonstrated that Akt signaling is responsible for MMP-2 activation (Jin et al., 2007). Our previous studies indicated a possible linkage between MMP and integrin-mediated migration during curcumin-suppressed chondrogenic differentiation of chick limb bud mesenchymal cells. Our on-going research will test the possible involvements of MMPs in curcumin-suppressed chondrogenesis.

In summary, for the first time, this study describes biological properties of curcumin during chondrogenic differentiation of chick limb bud mesenchymal cells. Curcumin suppressed chondrogenesis by stimulating apoptotic cell death. It also down-regulated integrin $\beta 1$ and lowered the phosphorylation level of FAK, which in turn lead to a reorganization of the actin cytoskeleton via modulation of Akt signaling.

\section{Methods}

\section{Cell culture and treatment}

Mesenchymal cells were derived from the distal tips of wing buds from Hamburger-Hamilton (Hamburger and Hamilton, 1992) stage 22/23 embryos of fertilized white Leghorn chicken eggs. The cells were micromass-cultured as described previously (Jin et al., 2007). Cells at $2 \times 10^{7}$ cells $/ \mathrm{ml}$ were plated onto 35 or $60 \mathrm{~mm}$ dishes in 3 or 19 drops of $15 \mu \mathrm{l}$ each. The cells were incubated for $1 \mathrm{~h}$ at $37^{\circ} \mathrm{C}$ under $5 \% \mathrm{CO}_{2}$ to allow attachment, and were then maintained in Ham's F-12 medium containing $10 \%$ FBS, $100 \mathrm{IU} / \mathrm{ml}$ penicillin and $50 \mu \mathrm{g} / \mathrm{ml}$ streptomycin (Gibco Invitrogen, Grand Island, NY). The cells were maintained in culture medium for the indicated time periods in the presence or absence of Curcumin (1,7-bis (4-hydroxy-3methoxyphenyl)1,6-heptadiene-3,5-dione) purchased from 
Sigma Chemical Company. Control cultures were exposed to solvent only.

\section{Analysis of cell condensation and differentiation}

Chondrogenic differentiation was measured by Alcian blue staining of sulfated cartilage glycosaminoglycans (GAG). To demonstrate the deposition of cartilage matrix proteoglycans, representative cultures were collected on day 5 of incubation and stained with $0.5 \%$ Alcian blue $8 \mathrm{GX}, \mathrm{pH} 1.0$ (Lev and Spicer, 1964; Hassell and Horigan, 1982). Alcian blue bound to sulfated GAG was extracted with $6 \mathrm{M}$ guanidine- $\mathrm{HCl}$, and quantified by measuring the absorbance of the extracts at $600 \mathrm{~nm}$. Binding of peanut agglutinin (PNA) was used as a specific marker for precartilage condensation. Briefly, cultures were rinsed twice with 0.02 M PBS, pH 7.2, fixed in methanol:acetone (1:1) for $1 \mathrm{~min}$, air-dried, and then incubated with $100 \mu \mathrm{g} / \mathrm{ml}$ biotinylated PNA (Sigma) for $1 \mathrm{~h}$. Bound PNA was visualized using the VECTASTAIN ABC and DAB substrate solution kit (Vector laboratories Inc., Burlingame, CA).

\section{Cell proliferation assay}

Proliferation of mesenchymal cells was determined by direct counting of cells from micromass cultures. Control and treated cultures were maintained for the indicated number of days, detached with trypsin/EDTA solution and counted in triplicate using a hemacytometer.

\section{Apoptosis assay}

Apoptosis was analyzed by flow cytometry (FACS Calibur, Becton-Dickinson, France). To detect the extent of propidium iodide staining, cells were excited at $488 \mathrm{~nm}$ and emission was detected at $585 \mathrm{~nm}$.

\section{Western blot analysis}

Total protein was prepared using RIPA buffer and Western blot analyses were performed. Thirty $\mu \mathrm{g}$ total protein was loaded and resolved by $10 \%$ SDS-PAGE gel. Proteins were transferred to a nitrocellulose membrane and probed with the following primary antibodies: (p)Akt, (Cell Signaling Technology Inc., Danvers, MA), type II collagen and FN (Sigma), integrin $\beta 1$ (BD Science, Franklin Lakes, NJ), (p)FAK ${ }^{397}$ (Covance, Princeton, NJ). Membranes were washed and incubated with the appropriate HRP-conjugated secondary antibodies (Santa Cruz). Signals were detected using enhanced chemiluminescence (Pierce Biotechnology inc., Rockford, MN). Three independent experiments were performed for all Western blot analyses.

\section{Actin staining}

Cells were micromass cultured on cover slips and treated with various chemicals as indicated in the figure legends, washed 3 times with PBS, then fixed and permeabilized as described above. Each culture was then stained with Alexa488-phalloidin (Molecular Probes, Eugene, OR) prepared in PBS containing $1 \%(\mathrm{v} / \mathrm{v})$ BSA for $1 \mathrm{~h}$ at room temperature in a lightproof box. The cultures were then washed 3 times with water and mounted with Gel/Mount (Biomedia, Foster City, CA). The slides were examined using a confocal microscope (MRC 1024/ES, Bio-Rad Laboratory, CA).

\section{Electroporation}

Vectors expressing HA-wild-type Akt1 (wt-Akt) or dominant inhibitory mutant Akt1 (mutant-Akt) were electroporated into isolated mesenchymal cells using a square wave generator (BTX-830; Gentronics, San Diego, CA) with 20 msec, 200 square pulses.

\section{Acknowledgements}

This study was sponsored by Wonkwang University in 2009.

\section{References}

Bae JH, Park JW, Kwon TK. Ruthenium red, inhibitor of mitochondrial $\mathrm{Ca}^{2+}$ uniporter, inhibits curcumin-induced apoptosis via the prevention of intracellular $\mathrm{Ca}^{2+}$ depletion and cytochrome $\mathrm{c}$ release. Biochem Biophys Res Commun 2003;303:1073-9

Balasubramanian S, Eckert RL. Curcumin suppresses AP1 transcription factor-dependent differentiation and activates apoptosis in human epidermal keratinocytes. J Biol Chem 2006;282:6707-15

Bernt C, Vennegeerts T, Beuers U, Rust C. The human transcription factor AP-1 is a mediator of bile acid-induced liver cell apoptosis. Biochem Biophys Res Commun 2006; 340:800-6

Chang SH, Oh CD, Yang MS, Kang SS, Lee YS, Sonn JK, Chun JS. Protein kinase $C$ regulates chondrogenesis of mesenchymes via mitogen-activated protein kinase signaling. J Biol Chem 1998;273:19213-9

Chen $\mathrm{H}$, Zhang ZS, Zhang YL, Zhou DY. Curcumin inhibits cell proliferation by interfering with the cell cycle and inducing apoptosis in colon carcinoma cells. Anticancer Res 1999; 19:3675-80

Chen YR, Tan TH. Inhibition of the c-Jun N-terminal kinase (JNK) signaling pathway by curcumin. Oncogene 1998; 17:173-8

Choi B, Chun JS, Lee YS, Sonn JK, Kang SS. Expression of protein kinase $C$ isozymes that are required for chondrogenesis of chick limb bud mesenchymal cells. Biochem Biophys Res Commun 1995;216:1034-40

Davies MA, Koul D, Dhesi H, Berman R, McDonnell TJ, McConkey D, Yung WK, Steck PA. Regulation of Akt/PKB activity, cellular growth, and apoptosis in prostate carcinoma cells by MMAC/PTEN. Cancer Res 1999;59:2551-6

DeLise AM, Fischer L, Tuan RS. Cellular interactions and signaling in cartilage development. Osteoarthritis Cartilage 2000;8:309-34 
Deodhar SD, Sethi R, Srimal RC. Preliminary study on antirheumatic activity of curcumin (diferuloyl methane). Indian J Med Res 1980;71:632-4

Dorai T, Dutcher JP, Dempster DW, Wiernik PH. Therapeutic potential of curcumin in prostate cancer--V: Interference with the osteomimetic properties of hormone refractory $\mathrm{C} 4-2 \mathrm{~B}$ prostate cancer cells. Prostate 2004;60:1-17

Felsenfeld DP, Schwartzberg PL, Venegas A, Tse R, Sheetz MP. Selective regulation of integrin--cytoskeleton interactions by the tyrosine kinase Src. Nat Cell Biol 1999;1:200-6

Gertsch J, Güttinger M, Heilmann J, Sticher O. Curcumin differentially modulates mRNA profiles in Jurkat $T$ and human peripheral blood mononuclear cells. Bioorg Med Chem 2003;11:1057-63

Guo H, Yu JH, Chen K, Ye ZQ, Liu GC. Curcumin-induced apoptosis in androgen-dependent prostate cancer cell line LNCaP in vitro. Zhonghua Nan Ke Xue 2006;12:141-4

Hamburger $\mathrm{V}$, Hamilton HL. A series of normal stages in the development of the chick embryo. 1951. Dev Dyn 1992; 195:231-72

Hanif R, Qiao L, Shiff SJ, Rigas B. Curcumin, a natural plant phenolic food additive, inhibits cell proliferation and induces cell cycle changes in colon adenocarcinoma cell lines by a prostaglandin-independent pathway. J Lab Clin Med 1997; 130:576-84

Hassell JR, Horigan EA. Chondrogenesis: a model developmental system for measuring teratogenic potential of compounds. Teratog Carcinog Mutagen 1982;2:325-31

Hayakawa J, Ohmichi M, Kurachi H, Kanda Y, Hisamoto K, Nishio Y, Adachi K, Tasaka K, Kanzaki T, Murata Y. Inhibition of BAD phosphorylation either at serine 112 via extracellular signal-regulated protein kinase cascade or at serine 136 via Akt cascade sensitizes human ovarian cancer cells to cisplatin. Cancer Res 2000;60:5988-94

Holy JM. Curcumin disrupts mitotic spindle structure and induces micronucleation in MCF-7 breast cancer cells. Mutat Res 2002;518:71-84

Hong RL, Spohn WH, Hung MC. Curcumin inhibits tyrosine kinase activity of p185neu and also depletes p185neu. Clin Cancer Res 1999;5:1884-91

Idowu BD, Knight MM, Bader DL, Lee DA. Confocal analysis of cytoskeletal organisation within isolated chondrocyte sub-populations cultured in agarose. Histochem J 2000; 32:165-74

Jaruga E, Bielak-Zmijewska A, Sikora E, Skierski J, Radziszewska E, Piwocka K, Bartosz G. Glutathioneindependent mechanism of apoptosis inhibition by curcumin in rat thymocytes. Biochem Pharmacol 1998;56:961-5

Jin EJ, Park KS, Bang OS, Kang SS. Akt signaling regulates actin organization via modulation of MMP-2 activity during chondrogenesis of chick wing limb bud mesenchymal cells. J Cell Biochem 2007;102:252-61

Karsenty G, Wagner EF. Reaching a genetic and molecular understanding of skeletal development. Dev Cell 2002; 2:389-406
Kawamori T, Lubet R, Steele VE, Kelloff GJ, Kaskey RB, Rao CV, Reddy BS. Chemopreventive effect of curcumin, a naturally occurring anti-inflammatory agent, during the promotion/progression stages of colon cancer. Cancer Res 1999;59:597-601

Khafif A, Schantz SP, Chou TC, Edelstein D, Sacks PG. Quantitation of chemopreventive synergism between (-) -epigallocatechin-3-gallate and curcumin in normal, premalignant and malignant human oral epithelial cells. Carcinogenesis 1998;19:419-24

Khanna S. Inversion of uterus through an upper segment scar. Br J Obstet Gynaecol 1999;106:1225-6

Kim D, Kim S, Koh H, Yoon SO, Chung AS, Cho KS, Chung J. Akt/PKB promotes cancer cell invasion via increased motility and metalloproteinase production. FASEB J 2001; 15:1953-62

Knudson CB, Knudson W. Cartilage proteoglycans. Semin Cell Dev Biol 2001;12:69-78

Korutla L, Kumar R. Inhibitory effect of curcumin on epidermal growth factor receptor kinase activity in A431 cells. Biochim Biophys Acta 1994;1224:597-600

Korutla L, Cheung JY, Mendelsohn J, Kumar R. Inhibition of ligand-induced activation of epidermal growth factor receptor tyrosine phosphorylation by curcumin. Carcinogenesis 1995;16:1741-5

Kuo ML, Huang TS, Lin JK. Curcumin, an antioxidant and anti-tumor promoter, induces apoptosis in human leukemia cells. Biochim Biophys Acta 1996;1317:95-100

Langelier E, Suetterlin R, Hoemann CD, Aebi U, Buschmann MD. The chondrocyte cytoskeleton in mature articular cartilage: structure and distribution of actin, tubulin, and vimentin filaments. J Histochem Cytochem 2000;48:1307-20

Lev-Ari S, Maimon Y, Strier L, Kazanov D, Arber N. Downregulation of prostaglandin $\mathrm{E} 2$ by curcumin is correlated with inhibition of cell growth and induction of apoptosis in human colon carcinoma cell lines. J Soc Integr Oncol 2006;4:21-6

Lev R, Spicer SS. Specific staining of sulphate groups with alcian blue at low pH. J Histochem Cytochem 1964;12:309

Li G, Lubin FD, McGee DW. alpha3beta1 integrin induced suppression of the Caco-2 epithelial cell IL-1 signaling pathway leading to NF-(kappa)B activation. Cell Immunol 2004;231:30-9

Liu JY, Lin SJ, Lin JK. Inhibitory effects of curcumin on protein kinase $\mathrm{C}$ activity induced by 12-O-tetradecanoyl-phorbol13-acetate in NIH 3T3 cells. Carcinogenesis 1993;14: 857-61

Maini PK, Solursh M. Cellular mechanisms of pattern formation in the developing limb. Int Rev Cytol 1991; 129: 91-133

Mehta K, Pantazis P, McQueen T, Aggarwal BB. Antiproliferative effect of curcumin (diferuloylmethane) against human breast tumor cell lines. Anticancer Drugs 1997; 8:470-81

Mohan R, Sivak J, Ashton P, Russo LA, Pham BQ, Kasahara $N$, Raizman MB, Fini ME. Curcuminoids inhibit the angio- 
genic response stimulated by fibroblast growth factor-2, including expression of matrix metalloproteinase gelatinase B. J Biol Chem 2000;275:10405-12

Mukhopadhyay A, Bueso-Ramos C, Chatterjee D, Pantazis $P$, Aggarwal BB. Curcumin downregulates cell survival mechanisms in human prostate cancer cell lines. Oncogene 2001;20:7597-609

Narasimhan M, Ammanamanchi S. Curcumin blocks RON tyrosine kinase-mediated invasion of breast carcinoma cells. Cancer Res 2008;68:5185-92

Oh CD, Kang SS, Ha MJ, Chun JS. Analysis of protein kinase $\mathrm{C}$ isoforms involved in the activation of laminin receptor in Raw264.7 macrophages. IUBMB Life 1999;48:439-43

Onodera S, Kaneda K, Mizue Y, Koyama Y, Fujinaga M, Nishihira J. Macrophage migration inhibitory factor up-regulates expression of matrix metalloproteinases in synovial fibroblasts of rheumatoid arthritis. J Biol Chem 2000;275: 444-50

Parsons JT, Martin KH, Slack JK, Boerner SA, Martin CC. Integrin connections map: to infinity and beyond. Science 2002;296:1652-3

Ramachandran C, You W. Differential sensitivity of human mammary epithelial and breast carcinoma cell lines to curcumin. Breast Cancer Res Treat 1999;54:269-78

Reddy S, Aggarwal BB. Curcumin is a non-competitive and selective inhibitor of phosphorylase kinase. FEBS Lett 1994; 341:19-22

Sandell LJ, Adler P. Developmental patterns of cartilage. Front Biosci 1999;4:D731-42

Sikora E, Bielak-Zmijewska A, Piwocka K, Skierski J, Radziszewska E. Inhibition of proliferation and apoptosis of human and rat T lymphocytes by curcumin, a curry pigment. Biochem Pharmacol 1997;54:899-907

Simon A, Allais DP, Duroux JL, Basly JP, Durand-Fontanier $\mathrm{S}$, Delage C. Inhibitory effect of curcuminoids on MCF-7 cell proliferation and structure-activity relationships. Cancer Lett
1998;129:111-6

Solursh M. Differentiation of cartilage and bone. Curr Opin Cell Biol 1989;1:989-94

Swailes NT, Knight PJ, Peckham M. Actin filament organization in aligned prefusion myoblasts. J Anat 2004;205:381-91

Troussard AA, Costello P, Yoganathan TN, Kumagai S, Roskelley CD, Dedhar S. The integrin linked kinase (ILK) induces an invasive phenotype via AP-1 transcription factor-dependent upregulation of matrix metalloproteinase 9 (MMP-9). Oncogene 2000;19:5444-52

Von der Mark K, von der Mark $\mathrm{H}$. The role of three genetically distinct collagen types in endochondral ossification and calcification of cartilage. J Bone Joint Surg Br 1977;59: 458-64

Wawro B, Greenfield NJ, Wear MA, Cooper JA, Higgs HN, Hitchcock-DeGregori SE. Tropomyosin regulates elongation by formin at the fast-growing end of the actin filament. Biochemistry 2007;46:8146-55

Woo JH, Kim YH, Choi YJ, Kim DG, Lee KS, Bae JH, Min DS, Chang JS, Jeong YJ, Lee YH, Park JW, Kwon TK. Molecular mechanisms of curcumin-induced cytotoxicity: induction of apoptosis through generation of reactive oxygen species, down-regulation of $\mathrm{Bcl}-\mathrm{XL}$ and IAP, the release of cytochrome $c$ and inhibition of Akt. Carcinogenesis 2003;24: 1199-208

Yamamoto $\mathrm{H}$. Interrelation of differentiation, proliferation and apoptosis in cancer cells. J Osaka Dent Univ 1995;29:51-60

Yoon YM, Oh CD, Kang SS, Chun JS. Protein kinase A regulates chondrogenesis of mesenchymal cells at the post-precartilage condensation stage via protein kinase C-alpha signaling. J Bone Miner Res 2000;15:2197-205

Zheng S, Chen A. Curcumin suppresses the expression of extracellular matrix genes in activated hepatic stellate cells by inhibiting gene expression of connective tissue growth factor. Am J Physiol Gastrointest Liver Physiol 2006;290: G883-93 